\title{
VALUING ACCURACY-FILLING OUT THE FRAMEWORK: COMMENT ON KAPLOW (2)
}

\author{
STEPHEN MCG. BUNDY*
}

$\mathrm{T}_{\mathrm{s}}$ in its judication is largely taken for granted." 1 Perhaps this was once true (although I doubt it), but today it is not. For at least two decades, leading judges, ${ }^{2}$ distinguished legal scholars, ${ }^{3}$ disputants, ${ }^{4}$ and even a few

* Professor of Law, School of Law (Boalt Hall), University of California, Berkeley. For comments on earlier drafts, thanks to Willy Fletcher, Louis Kaplow, and Andrea Peterson and special thanks to Daniel Chess, Jan Vetter, and David Caron. Errors are mine. Presented at the John M. Olin Program in Law and Economics Conference on "Economic Analysis of Civil Procedure" at the University of Virginia School of Law, March 26-27, 1993.

${ }^{1}$ Louis Kaplow, The Value of Accuracy in Adjudication, 23 J. Legal. Stud. 307, at 307 (1994).

${ }^{2}$ See, for example, Jon O. Newman, Rethinking Fairness: Perspectives on the Litigation Process, 94 Yale L. J. 1643, 1648-52 (1985) (arguing that value of marginal increases in accuracy may not be worth their cost); Henry J. Friendly, "Some Kind of Hearing," 123 U. Pa. L. Rev. 1267, 1276 (1975) (more accurate determination not worth cost when amount at stake is small). Much of former Chief Justice Burger's advocacy on behalf of judicial reform can be seen as a concern about unwarranted expenditures in pursuit of marginal gains in accuracy. See Warren E. Burger, Agenda for 2000 A.D.-a Need for Systematic Anticipation, in The Pound Conference: Perspectives on Justice in the Future 23 (A. Levin \& R. Wheeler eds. 1979); see also id. at $28 \&$ n.2 (discussing "wasteful" three-judge courts); $i d$. at 33 (urging greater use of arbitration); id. at 34 ("probate procedures can be simplified without diminishing certainty of title").

${ }^{3}$ Deborah Rhode, Ethical Perspectives on Legal Practice, 37 Stan. L. Rev. 589, 635 (1985) (arguing that lawyers' fee incentives frequently lead them to overinvest in accuracy); Derek Bok, A Flawed System of Law Practice and Training, 33 J. Legal Educ. 570, 571-73 (1983) (arguing that investments in litigation are frequently unjustified because adjudication has no effect on real-world behavior). In view of Bok's astringent comments on the cost of National Labor Relations Board (NLRB) proceedings to which his own institution was a party (see $i d$.), his comments are perhaps more accurately interpreted as those of a disputant.

${ }^{4}$ See, for example, Robert Eli Rosen, The Inside Counsel Movement, Professional Judgment and Organizational Representation, 64 Ind. L. Rev. 479, 511 (1989) (arguing that the increased corporate use of in-house counsel is intended, in substantial part, to reduce unproductive expenditures in pursuit of greater accuracy).

[Journal of Legal Studies, vol. XXIII (January 1994)]

(C) 1994 by The University of Chicago. All rights reserved. 0047-2530/94/2301-0016\$01.50 
economists ${ }^{5}$ have vigorously questioned whether American adjudication spends too much time and treasure in pursuit of factual truth. At the same time, individuals and institutions have increasingly chosen (or been forced) to resort to simplified dispute resolution procedures, both in and out of court. ${ }^{6}$ While not every form of alternative dispute resolution reflects doubts about the marginal value of greater accuracy, ${ }^{7}$ some of those private and public choices must have involved an explicit-although perhaps ill-informed-trade-off between improved factual accuracy and other values. On any fair reading, then, accuracy's value is everywhere in issue.

Kaplow is surely right, though, that we lack a well-developed framework for deciding how much avoiding factual errors is worth. Most procedural regimes intuitively treat the value of accuracy as proportional to the stakes. Thus, in suits for money damages, the value of accuracy is directly proportional to the amount in controversy; in suits for injunctive relief, to the consequences of granting or denying the injunction; in criminal cases, to the severity of the sentence, with capital cases demanding the greatest investment. These rough measures have sometimes also proved appealing to procedural reformers ${ }^{8}$ and economists. ${ }^{9}$

Kaplow's article aims at and achieves something better. He provides an economic analysis of how reducing random error creates value, both by improving direct deterrence of primary conduct ${ }^{10}$ and by reducing the

\footnotetext{
${ }^{5}$ Robert D. Cooter \& Daniel L. Rubinfeld, Economic Analysis of Legal Disputes and Their Resolution, 27 J. Econ. Literature 1067, 1088 (1989) ("A central normative issue in discussions of legal procedure is balancing the cost of additional information against the benefit of reducing court errors. There is reason to wonder whether disputants value cumbersome procedural rules designed to produce accuracy as highly as do courts." ); see also id. at 1094 (economic analysis of tort law "all too often provided efficiency proofs for institutions that most lawyers now view as inefficient").

${ }^{6}$ See generally Stephen B. Goldberg, Frank E. A. Sander, \& Nancy H. Rogers, Dispute Resolution: Negotiation, Mediation, and Other Processes (2d ed. 1992).

${ }^{7}$ The evidence is equivocal because, as Kaplow points out, some simplified procedures may produce equal accuracy at reduced cost and others, such as resort to a neutral expert, may actually increase accuracy. Kaplow, supra note 1, at 333-34 \& n.70.

${ }^{8}$ Frank E. A. Sander, Varieties of Dispute Processing, in The Pound Conference, supra note 2, at 65, 77 (the "amount in controversy has been an item consistently looked to to determine the amount of process that is 'due' ').

${ }^{9}$ Compare Richard A. Posner, The Economic Analysis of Law $\$ 21.1$ at 430 (2d ed. 1977) (arguing that "as a first approximation ... the cost of error in an individual case will be large" when the stakes are large), with Richard A. Posner, The Economic Analysis of Law $\S 21.1$ at $517-18$ (3d ed. 1986) (dropping this point).

10 Throughout I describe conduct as primary, predispute, and ex ante interchangeably to indicate the time before the dispute has arisen when the parties are engaged in "real world" conduct. I use the terms "postdispute" and "ex post" interchangeably to describe conduct after the dispute has arisen. To the extent this differs from conventional economic usage, readers are warned.
} 
costs of maintaining any given level of direct deterrence. Within his chosen framework, the article generates new and important results. Moreover, given its assumptions, its logic seems unassailable.

For me, the article stirs two reactions: admiration for its scope, imagination, and rigor, and concern that it may be misunderstood or misused. The latter concern stems from two aspects of the article. First, it is clearly intended to bring Kaplow's technical findings to the ongoing nontechnical debate among lawyers and laymen about procedural reform, which has centered on civil cases. I believe that audience will draw from the article the message that accuracy is overvalued, especially in civil actions for money damages. Second, Kaplow has had to make a number of framing assumptions, some dictated by his choice of an economic methodology and some, undoubtedly, by concerns of manageability. While most of the assumptions are apparent on the face of the article, what may be less apparent is that each assumption tends to yield a reduced value for accuracy and that their cumulative effect may cause Kaplow's account seriously to understate that value.

This article is therefore intended as a reader's companion to Kaplow's project. Ignoring many interesting findings and complications, ${ }^{11}$ I focus on the heart of the enterprise, his systematic attempt to specify when procedures that reduce random error in fact-finding will generate value sufficient to justify their costs. My aim is not to refute Kaplow's account ${ }^{12}$ but rather to show both its limits and what role it might play in a more complete and plausible valuative framework.

The argument proceeds as follows. Section I sets out a brief nontechnical account of Kaplow's chosen analytic framework and essential conclusions. Because Kaplow's article is very long, complex, and detailed, the account may help to make his basic ideas accessible. More important, it makes clear the directions that must be pursued to develop a fuller picture.

Section II then broadens the framework. The most important omitted consideration, in my judgment, is systemic bias. In Section ILA I argue that systemic bias presents more fundamental and intractable problems for American procedure than random error does and that, where present, it will generally tend to have more harmful effects on primary conduct that does random error. In Section II $B$ I show how accuracy can often influence primary conduct indirectly, through mechanisms other than its

\footnotetext{
11 For example, I do not discuss Kaplow's important analyses of the relation between accuracy and the level of sanctions, of the relation between accuracy and the burden of proof, or of the relation between accuracy and the right to appear.

12 Indeed, Kaplow notes many of these omissions explicitly, and what he has to say about those he discusses suggests he might agree with much of what is said here.
} 
effect on the expected or actual judgment in an actor's own case, and argue that such indirect effects will normally be desirable. In Section IIC I argue that accuracy will generally have desirable effects on the disputing behavior of claimants and defendants. Finally, in Section IID I briefly show how an expanded account of accuracy's influence on behavior can illuminate other nonbehavioral values served by accuracy.

Section III briefly shows how an expanded account might alter the valuation of particular procedures that reduce random inaccuracy. In many instances, I argue, the expanded account will indicate a greater value for procedures that reduce random error than does Kaplow's account. In a few instances, however, the need to prevent systemic bias might justify procedures that increase random error precisely in those settings where Kaplow's account predicts that such procedures would be avoided.

\section{Kaplow's Account: Assumptions and Results}

\section{A. Assumptions}

Kaplow's inquiry into the value of accuracy is framed by four more or less explicit structural choices. First, improved accuracy is defined as a move from being right on average toward being exactly right every time. ${ }^{13}$ This definition explicitly excludes the problem of systemic bias. ${ }^{14}$

Second, the positive value of accuracy is reflected solely in improved behavior resulting from improved deterrence. Behavioral improvements generated by means other than deterrence are excluded. Except for a brief discussion of possible consequences of giving special weight to avoiding conviction of the innocent, nonbehavioral values are also excluded. ${ }^{15}$

Third, improved accuracy influences deterrence only through its direct effect on the expected decision of the tribunal in the actor's own case. Accurate findings in other cases have no influence on her conduct, nor can findings in her case influence the conduct of others.

Fourth, in determining improved accuracy's deterrent value, only im-

\footnotetext{
${ }^{13}$ In determining damages, increased accuracy in Kaplow's account allows the tribunal to move from awarding damages that represent an accurate average figure for the entire class of injured persons to awarding actual damages for each person. In determining liability, increased accuracy allows the tribunal to reduce the frequency or magnitude of errors around a mean evaluation that is already accurate for the class of conduct in dispute.

${ }^{14}$ Kaplow, supra note 1, at 312-13 \& n.9; see also id. at 389-90. For discussion of Kaplow's views concerning this omission see note 32 infra.

15 Kaplow, supra note 1 , subsection VB1, at 386.
} 
provements in primary conduct count. No weight is given to effects of accuracy on behavior in the disputing process. ${ }^{16}$

Within this framework, Kaplow's account deepens the prior analysis of accuracy's role in improving behavior and expands it to consider issues of cost reduction and party incentives.

\section{B. The Deterrent Effect of Increased Accuracy on Primary Conduct}

The article's contribution to understanding the value of accuracy's deterrent effect on primary conduct is best appreciated against the background of prior work. It has long been a staple of law and economics analysis that improving accuracy improves deterrence. Greater accuracy should reduce both false positives (lowering expected sanctions for lawful or desirable behavior) and false negatives (raising expected sanctions for unlawful or undesirable behavior) ${ }^{17}$ In consequence, behavioral incentives should improve.

In their work on legal advice in litigation, Kaplow and Shavell found a fly in this ointment. Improved expected sanctions resulting from greater accuracy will not improve actors' primary conduct, unless actors actually predict the consequences of greater accuracy for their case before they decide how to act. ${ }^{18}$ Where primary actors are "ignorant of the law,", 19 later expenditures on accuracy will be worthless.

This pessimistic view turns out, however, to be incomplete. ${ }^{20}$ To begin with, imperfectly informed primary actors often have access to legal advice, so that it is possible to predict how accuracy will alter the outcome of their case. Moreover, because accuracy increases the difference between the expected sanctions for desirable and undesirable conduct, it increases the value of being right about which is which. Greater accuracy, however vaguely known, should therefore spur actors to find out whether

16 Thus, the core argument excludes the effect of accuracy on frivolous or baseless claims (see id. at 312 \& n.7, 370-71 \& n. 184) and on settlement. Id. at 342-43 (explaining why the exclusion has no clear implications for the validity of the argument).

17 See, for example, the sources cited in Kaplow, supra note 1, at 348 \& n.118.

18 Louis Kaplow \& Steven Shavell, Legal Advice about Information to Present in Litigation: Its Effects and Social Desirability, 102 Harv. L. Rev. 567, 588 (1989) (greater accuracy will not improve behavior unless "at the time they contemplate how to act, individuals understand what information tribunals will later obtain and what sanctions will then be applied') (emphasis in original).

${ }^{19}$ Id. at 589 \& n.59.

${ }^{20}$ For the full argument, see Stephen McG. Bundy \& Einer Richard Elhauge, Do Lawyers Improve the Adversary System? A General Theory of Legal Advice and Its Regulation, 79 Calif. L. Rev. 313, 381-82 (1991). 
or not their conduct is sanctionable and, where legally relevant, how much harm they will do. Greater accuracy thus improves both the quality of the signal that adjudication sends to primary actors and the likelihood that they will receive it.

The main force of Kaplow and Shavell's observation about accuracy's complete ineffectiveness in controlling those "ignorant of the law" thus appears to be confined to two limited classes of actors. The first consists of those who have no idea that their conduct is sanctionable, so that they never even think to seek legal advice (which would necessarily inform them about accuracy) or have occasion to apply their own commonsense laypersons' understandings of accuracy's effects. The second consists of actors aware that their conduct may be sanctionable, but for some reason wholly unaware of the effect of increased accuracy, perhaps because that effect is very small and they cannot afford the legal advice that would enable them to discern it. For short I will refer to both these classes of actors as wholly uninformed.

To these categories of actors wholly unaffected by accuracy, Kaplow now adds two more. One is the class of actors who cannot determine how the law will treat them because their expected sanction depends on harm caused or suffered and they do not know (and cannot find out) precisely how much harm they will cause or suffer. Where a risk-neutral actor can estimate only the average harm she will cause or suffer, then knowing that after the fact the tribunal will determine the exact level of harm (which may be higher or lower than average) will have no implications for her behavior and will not alter it. Accordingly, expenditures on accuracy to allow the tribunal to award exact damages will be wasted. ${ }^{21}$ For short I will refer to such actors as poor harm predictors.

There will also be a class of actors whose conduct will not be altered even if they can predict the full consequences of accuracy for their case. Even cynical "bad persons" vary in the benefit they expect from an act, net of expected sanctions. And many actors are strongly predisposed to commit or avoid acts wholly independent of any risk of sanctions, for example, because they believe in obeying the law. Where the propensity to engage in an act is very strong or very weak relative to expected sanctions without accuracy, an increase or decrease in expected sanc-

\footnotetext{
${ }^{21}$ In contrast, for risk-averse actors, knowing that the tribunal will award actual rather than average damages has implications for behavior even if it is impossible to predict that harm exactly. But those implications are not all benign: predictable accuracy will tend to improve the behavior of risk-averse claimants, because it ensures them full compensation, and to worsen that of risk-averse defendants, because it subjects them to the risk of an above average award. Kaplow, supra note 1, at 320-21.
} 
tions due to improved accuracy may not change the actor's conduct. ${ }^{22}$ For short I will refer to such actors as nonresponsive.

Finally, Kaplow properly stresses the need to carefully account for those beneficial behavioral effects that do occur. Even when the effects of accuracy are predicted and actually change behavior, the value of those changes must be measured rather than simply assumed. ${ }^{23}$ Moreover, the accounting must reflect the costs of accuracy. Those costs include not just the costs of generating more accurate outcomes but in addition the costs of actors' learning about the consequences of accuracy for their case. The net positive value of accuracy thus consists of the value of the behavioral improvements generated by accuracy, less the sum of generation costs and learning costs. ${ }^{24}$

These observations structure a hierarchy for the presumptive value of accuracy in improving primary conduct. Accuracy in determining how much harm an actor did sits at the bottom because actors often do not know (or will find it very costly to predict) precisely how much harm their conduct will cause. ${ }^{25}$ The paradigm cases are reckless driving or the discharge of a chemical whose toxic effects are poorly understood.

Accuracy in determining liability stands at the second level. The reason is that, while actors often may have only a general idea of how much harm their actions will cause, they usually know what they are going to do. Accordingly, learning costs should be lower. Kaplow thinks that desirable behavioral effects are particularly likely when accuracy is improved in criminal cases, because even actors without access to advice often have a commonsense understanding whether their conduct is sanctionable. ${ }^{26}$ In consequence, improved deterrence is unlikely to be wasted on the wholly ignorant.

Accuracy in determining future rights and obligations is the most likely to provide cost-justified improvements in behavior. The paradigm cases here are those involving awards of government licenses or benefits, certain actions for injunctive relief, and criminal cases in which the sentence involves incapacitation or death. In such cases, improved accuracy is reflected directly in the terms of the judgment. Because parties will have

22 Id. at 314, 340-41 \& n.95.

${ }^{23} \mathrm{Id}$. at 314 (discussing behavioral changes in response to more accurate damage awards); id. at 370-72 (formula for determining value of changed behavior resulting from greater accuracy in government benefits program).

${ }^{24}$ Id. subsection ILA2b, at 318 .

${ }^{25}$ Id. at 330 ("it is often the case that individuals can know at most the probability distribution of consequences of their acts"').

${ }^{26} I d$. subsection III $D 1$, at 366 . 
been through the litigation that produced the order or judgment and will ordinarily have legal advice about its terms, few will be wholly uninformed, and learning costs are likely to be very low. Therefore, the net behavioral benefits of accuracy will tend to be higher. But even in such cases, Kaplow stresses, one must carefully net out the costs and benefits of altered behavior to determine the value of what has been accomplished. ${ }^{27}$

\section{Accuracy as a Substitute for Other Costly Enforcement Mechanisms}

Kaplow's analysis of the role of accuracy in reducing costs is wholly novel. The basic point is that when accuracy, whatever its cost, has positive net benefits in improving behavior, it may be an attractive substitute for other more costly means of obtaining the same behavioral improvement. In particular, improving accuracy can be a less costly substitute for increasing the rate at which suspected wrongdoers (whether civil or criminal) are apprehended and prosecuted. The greater the relative cost advantage of accuracy, the more it should be substituted for enforcement. ${ }^{28}$ The potential savings from substitution will be especially substantial when sanctions are themselves costly to impose because for any given level of deterrence, increased reliance on accuracy to achieve that level will result in decreased total imposition of sanctions. ${ }^{29}$ Hence, accuracy is likely to be a valuable substitute for enforcement efforts in criminal cases because criminal sanctions, notably imprisonment, are very costly.

\section{Incentives}

One implication of the naive view that the value of increased accuracy is proportional to the stakes is that parties' incentives to seek accuracy in litigation are also roughly appropriate. Litigants will pay for improved accuracy so long as the resulting change in the expected judgment is greater than the cost of obtaining it. If the expected judgment is the measure of social value, then expenditures on accuracy will cease when

${ }^{27}$ Id. at $370-72$.

28 Id. subsection IIL $A 1 \mathrm{~b}$, at 351 .

${ }^{29}$ The combination of reduced enforcement rates and increased accuracy means that fewer innocent persons will be apprehended and fewer of those apprehended will be sanctioned, reducing expected sanctions for the innocent. For guilty actors, reduced enforcement rates will tend to reduce the number sanctioned, but increased accuracy will tend to increase the number. The former effect, however, must dominate the latter, because otherwise expected sanctions for the guilty would increase, which would violate the condition that deterrence (that is, the difference between expected sanctions for the innocent and the guilty) be held constant. Id. at 353-54 \& n. 129. 
the social value of accuracy is exhausted. Kaplow's account shows, however, that the change in the expected private value of the judgment can be a poor measure of the net social value of increased accuracy in improving primary conduct, especially when actors are wholly ignorant, poor predictors, or nonresponsive or when learning costs are high. In such cases, the alteration in the judgment will often overstate the value of accuracy, so the incentive to pay for accuracy is too high. ${ }^{30}$ Where parties are aware of circumstances which reduce the deterrent value of accuracy, Kaplow argues, both can benefit from agreeing before any dispute arises to a procedure in which each side's opportunity to present information is limited, because such an agreement can reduce the expected cost of litigation without weakening incentives to comply with legal obligations.

Where the issue is cost reduction through substitution, the private value of the expected change in the expected judgment may undervalue accuracy because it ignores public savings resulting from reduced enforcement effort or reduced use of costly sanctions. ${ }^{31}$ This result seems particularly likely for criminal defendants, who bear only part of the social cost of sanctions.

\section{EXPANDING THE AcCount}

Each of the principal assumptions in Kaplow's account results in omitting some desirable effects of accuracy. This section examines those omissions and sketches some of their consequences.

\section{A. Systemic Bias, Direct Deterrence of Primary Conduct, and Enforcement Costs}

Kaplow's account expressly omits the issue of systemic bias. ${ }^{32}$ It assumes that before any costs are incurred to improve accuracy, the outcomes for any particular kind of litigation are already accurate on aver-

\footnotetext{
${ }^{30}$ An important exception in which incentives will be inadequate is that in which increased accuracy, if anticipated at the time of defendant's act, would result in deterring a defendant's harmful conduct but the increase in plaintiff's expected judgment is less than the plaintiff's cost of obtaining accuracy. Id. at 340-42 \& n.95.

${ }^{31}$ Id. at 367.

32 Kaplow explicitly notes the omission, and in subsection VC3 he briefly considers some of its possible implications. The critical conclusions are that considering systemic bias "may affect an assessment of how valuable accuracy is in a given context or the determination of how accurate various procedures would be in practice, and also complicate the economic analysis." Kaplow, supra note 1 , at 398 \& nn. 272 \& 274 . What I have to say here shows both that Kaplow's comments are true within his chosen analytic framework and how they are true. In addition, it casts light on the adequacy of his analytic framework to do justice to the value of accuracy. I will indicate in my argument the respects in which Kaplow's brief analysis of the issue parallels my own.
} 
age. Improved accuracy thus consists of refinements that improve the tribunal's ability to recognize distinctions or reduce random error around that accurately set mean value. This amounts to an assumption that adjudicative procedures are not systemically skewed in favor of or against particular classes of litigants based on legally irrelevant factors such as their political views or influence or their religion, class, race, or gender.

In leaving aside systemic bias, Kaplow has assumed the existence of a kind of neutrality whose achievement historically has presented perhaps the most difficult practical and moral problem in American procedure. ${ }^{33}$ Moreover, as the endless succession of controversial cases involving issues of systemic bias, ${ }^{34}$ recent empirical studies, ${ }^{35}$ and even the economic literature $^{36}$ all demonstrate, it is very much a live problem. ${ }^{37}$

Where systemic bias exists, eliminating it will often have desirable deterrent effects on primary conduct when eliminating random error would not, for three reasons. First, actors are less likely to be wholly ignorant of systemic bias, even if actors have no legal advice or advice is very costly. Systemic bias will often have a deeper continuity with familiar features of the nonlitigation social landscape than the often arcane procedural choice between levels of resolving power in litigation. Moreover, while the level of random error may vary greatly across subject areas, systemic bias may well be present in all cases involving class or race issues, so that even unsophisticated actors learn of it without legal advice. Because victims of systemic bias often suffer more from

${ }^{33}$ For historical accounts, focusing on problems of class bias, see Edward Purcell, Litigation and Inequality: Federal Diversity Jurisdiction in Industrial America, 1870-1958 (1992); Jerold Auerbach, Unequal Justice: Lawyers and Social Change in Modern America (1976).

${ }^{34}$ In criminal cases, one might start with Leo Frank or the Scottsboro Boys and conclude with the Reginald Denny trial. In civil cases, one thinks of the school desegregation cases and the Dalkon Shield litigation, among others.

${ }^{35}$ See Audrey Chin \& Mark A. Peterson, Deep Pockets, Empty Pockets: Who Wins in Cook County Jury Trials, at viii-ix (1985) ("Litigants' race seemed to have a pervasive influence on the outcomes of civil jury trials in Cook County"); see also Report of the New York State Judicial Commission on Minorities (April 1991); The Preliminary Report of the Ninth Circuit Gender Bias Task Force (discussion draft, July 1992).

${ }^{36}$ Cooter \& Rubinfeld, supra note 5, at 1089 (discussing empirical evidence and speculating that "[p]erhaps courts impose rules that are too cumbersome in an effort to reduce random inaccuracy, whereas bias is the serious concern").

37 There are obviously real difficulties in deciding when systemic bias is operating, the extent of its effects, and the appropriate corrective measures. These issues will look very different if the problem is characterized as occasional prejudice on the part of a tribunal than if it is seen as a structural feature reflected in basic patterns of opportunity and distribution of social resources, which in turn affect aversion to risk, ability to recognize that one has been injured, and capacity to finance and manage litigation. For the most part, I put those issues aside here. 
bias than majority actors gain from it, ${ }^{38}$ they are especially likely to be aware of its existence. ${ }^{39}$

Second, the adverse behavioral effects of systemic bias is not eliminated when actors are poor harm predictors. Take one of Kaplow's strongest cases for the low deterrent value of reducing random error, the reckless driver who does not know precisely how much harm he will cause. ${ }^{40}$ Suppose all persons who break legs in auto accidents suffer, on average, $\$ 1,000$ in damages and, as in Kaplow's account, all victims recover damages. In Kaplow's account, expenditures that enable the tribunal to determine actual damages are a complete waste, even if actors know the law, unless actors also know (or can find out) precisely how much damage they will cause. ${ }^{41}$ Now suppose that 10 percent of the population are African Americans who recover only $\$ 750$ on account of systemic bias and that the other 90 percent are white and receive the full award. Results are no longer accurate on average. For those who know what the tribunal will do, deterrence of bad driving is too low because expected damages of $\$ 975$ do not reflect average harm. ${ }^{42}$ Unlike in Kaplow's account, this bad outcome can be predicted even when actors do not know how much harm they will cause. ${ }^{43}$

The potential effect of systemic bias will be worse if actors can predict who they will injure. Take another of Kaplow's examples, the chemical manufacturer who can predict the average harm caused by a toxic discharge but not actual harm. ${ }^{44}$ In Kaplow's account, a costly determination of actual rather than average damage is a waste. But if African Americans recover only 75 percent of their average damage and chemical companies can determine the racial composition of the communities where they locate their plants, ${ }^{45}$ the effects of systemic bias on expected sanctions

\footnotetext{
38 This parallels Gary Becker's point that "when the majority is very large relative to the minority ... market discrimination by the majority hardly lowers its incomes, but may greatly reduce the incomes of the minority." Gary S. Becker, Nobel Lecture: The Economic Way of Looking at Behavior, 101 J. Pol. Econ. 385, 388 (1993).

39 The differential visibility of bias to beneficiaries and victims is a staple of the scholarship of critical race theory. See, for example, Patricia J. Williams, The Alchemy of Race and Rights: Diary of a Law Professor 44-51, 102-6 (1991).

${ }^{40}$ Kaplow, supra note 1 , subsection IIA Ic, at 315.

${ }^{41}$ I am putting aside here the issue of risk-neutrality.

42 The mechanism by which that message is communicated is more likely, in this hypothetical at least, to be insurance rates rather than legal advice.

${ }^{43}$ In his brief discussion of the issue, Kaplow indicates agreement with this view. Kaplow, supra note 1 , at 398 \& n.274.

44 Id. subsection ILA la, at 313-14.

45 The company might not even need to identify the race of its victims. If the pattern of jury awards from the community were lower, the company might choose to locate there without determining the racial composition of the population.
} 
become more grave. For now, instead of deterrence being slightly low for all victims, it is appropriate for white communities but greatly reduced for African American communities. In this case, as in the auto personal injury case, expenditures to eliminate bias can improve behavior even when expenditures to reduce random error would not.

Finally, actors may well be more responsive to sanction alterations caused by systemic bias, at least when harm-causing actors can predict the race of the victim. For when systemic bias is an issue, nondeterrence controls on the behavior of actors, such as empathy for victims and felt moral obligations to them, often will also be weaker. ${ }^{46}$ Returning again to the chemical company, it is not hard to imagine that its executives will feel less moral compunction about the consequences of polluting a predominantly minority community. Where that is the case, sanctions are more important in controlling behavior, and reduced sanctions are more likely to have harmful behavioral effects.

The greater potential effect of systemic bias on behavior means that within Kaplow's framework it is less likely that parties' incentives to spend on procedures that reduce bias will be too high. It also suggests that expenditures to eliminate bias may sometimes be attractive substitutes for expanded enforcement efforts when expenditures to eliminate random error would not. Moreover, if (as I will shortly argue) other behavioral and nonbehavioral harms of systemic bias are also more severe than those associated with random error, that can only strengthen the case for substitution.

\section{B. Indirect Effects on Primary Conduct}

Kaplow's account treats the signal generated by an accurate outcome as a laser beam narrowly focused on the precise actors who will be bound by an expected or actual final judgment. Moreover, it considers only the deterrent effect of that signal. But accuracy can also have spillover effects on the primary conduct of actors other than the litigants, and in general those effects should be desirable. Two mechanisms seem most important: improved deterrence due to precedential effects and nondeterrence effects on willingness to comply with the law.

First, an accurate judgment in one case may guide future primary conduct in different cases presenting similar issues. Kaplow views the potential for precedential effects as limited to findings of harm caused rather than findings of liability. Even with respect to findings of harm, he doubts such effects occur very often, noting that many cases settle and that both

46 Williams, supra note 39 , at 19-27 (linking racism and lack of empathy). 
settlements and judgments are often inscrutable. ${ }^{47}$ My sense is somewhat different. Many litigation outcomes are public. In personal injury cases, for example, most verdicts and many settlements are collected and circulated in reporting services. And even when outcomes are private, they can have important carryover effects on primary conduct if one of the parties is a "repeat player" or if the lawyers who are involved in the litigation go on to represent other parties with similar problems. Nor is it true, in my judgment, that only information about harm caused has precedential value. Information concerning the harm caused by another actor is often useless in deciding what to do unless one is clear what the other actor did to cause the harm. Where accuracy is valuable in generating information on harm caused, therefore, accuracy in determining the facts bearing on liability will also be useful. ${ }^{48}$

Second, accuracy may influence primary conduct indirectly by affecting actors' propensity to comply with the law for reasons independent of its deterrent effect. ${ }^{49}$ Social psychological research indicates that individ-

${ }^{47}$ Kaplow, supra note 1, subsection IIB2c \& n.90.

48 Accuracy in determining the facts can also have valuable spillover effects on the clarity with which people understand their legal obligations. Kaplow does not note this issue because he draws a sharp distinction between finding the facts and determining "the appropriate content of the law." Id. at 338, n.86. However, at least in American procedure, measures that improve accuracy in fact-finding can simultaneously improve accuracy in applying settled principles of law. The reason is that first-instance fact finders (both judge and jury) often have nonreviewable discretion in determining the precise content of the legal rule. Sometimes this law-making power is legally sanctioned. In civil cases, juries are sometimes expressly granted the power to determine the legal standard of care, even on undisputed facts. Sioux City \& Pacific R. Co. v. Stout, 84 U.S. (17 Wall.) 657 (1873). Sometimes it is not officially approved, but nonetheless permitted. In criminal cases, of course, the jury's power to nullify the law in favor of a defendant is well known: a jury verdict of acquittal cannot be overturned however contrary to law. More significant, in both criminal cases whose outcome is conviction and civil cases whatever the outcome, the exceptionally deferential standard applied in reviewing jury fact-finding means that often the jury can, if it chooses, conclude that the facts would call for a particular result under the announced rule of law and then covertly apply a rule that produces a different result, without being reversed for doing so.

The carryover effect from accurate fact-finding to accurate law application seems especially likely in the case of procedural rules that protect against systemic bias. Where such a functional linkage exists and primary actors can observe the outcome of the case, procedures that promote accurate fact-finding will influence the accuracy with which legal rules are communicated to primary actors. For example, the jury in Pennzoil v. Texaco clearly had law-applying discretion as a consequence of its fact-finding discretion. If that lawapplying discretion was applied in a biased fashion, as some accounts of the case suggest, then conduct in the market for corporate control may well have been adversely affected. Similarly, to the extent that the settlement in Office of Thrift Supervision v. Fishbein was influenced by the expectation that the federal administrative law judge would exercise law-applying discretion in a biased manner, the conduct of lawyers for financial institutions may have been adversely affected. In either case, it is likely that steps to reduce bias in fact-finding would also reduce bias in law application.

${ }^{49}$ See id. subsection VC2 (noting this possibility and its exclusion from his account). 
uals can and do distinguish between whether outcomes in litigation serve their interests and whether those outcomes are substantively or procedurally fair. Those fairness judgments in turn influence reported compliance with the law.

Both the reduction of random error and the elimination of bias seem likely to enhance judgments of outcome fairness in ways that improve compliance behavior, and eliminating bias is especially likely to have that effect. The major measured contributors to compliance are judgments of distributive fairness and of legitimacy. ${ }^{50}$ One might think that judgments of distributive fairness would respond strongly to the presence or absence of perceived systemic bias. ${ }^{51}$

Individuals' judgments of legitimacy are reportedly most strongly affected by perceived procedural fairness. Perceived procedural fairness in turn is influenced by the perceived "quality" of the judgment, which appears to measure accuracy in Kaplow's narrow sense. But it is much more strongly influenced by the perceived absence of bias in the decision maker. ${ }^{52}$

How strong these compliance effects are in practice remains in doubt, even for persons who have had direct experience of litigation. ${ }^{53}$ After all, ignorance and nonresponsiveness can in theory dilute the effect of accuracy on voluntary compliance in the same way that they dilute the effect of accuracy on deterrence. For economists skeptical of those effects, however, it is worth noting that in the leading study legitimacy had a significantly greater influence on reported compliance with the law than did deterrence. ${ }^{54}$

\section{Effects on Disputing Behavior}

The design of Kaplow's model excludes behavior after a dispute has arisen because all injured persons claim, all cases are tried, and compliance with the judgment is not an issue. Investing in accuracy will, however, often improve behavior after the dispute has arisen, either in the

so Tom R. Tyler, Why People Obey the Law, at 102-12 (1990); E. Allen Lind \& Tom R. Tyler, The Social Psychology of Procedural Justice 76-81, 211 (1988).

51 According to Tyler "distributive fairness" reflects an evaluation of public policies in terms of whether they "distribute government benefits and burdens fairly." Tyler, supra note 50 , at 73 .

${ }^{52}$ See id. at 137-38 (authorities" "effort to be fair" more important to judgments of fairness than "quality of the decision").

53 Compare id. at 67 ("the conclusions reached here probably understate the importance of normative factors on compliance'), with Lind \& Tyler, supra note 50, at 211 ("salutary behavioral consequences are by no means so certain as salutary attitudinal effects").

54 Tyler, supra note 50 , at 57-62. 
same case or in other related cases. Those improvements may in turn have effects on primary conduct.

Sometimes increased accuracy may actually improve deterrence of undesirable litigation conduct. Take frivolous claims, which raise expected sanctions for desirable primary conduct. Kaplow notes that greater accuracy on the merits may discourage frivolous suits but also that because accuracy involves increased defense costs it might sometimes encourage them. ${ }^{55}$ While demonstrating that greater accuracy will generally improve deterrence of frivolous claims is beyond the scope of this article, ${ }^{56}$ there are at least two reasons for optimism. First, improved accuracy on the merits will often translate into improved accuracy in assessing frivolousness. The critical question in assessing frivolousness is how much the plaintiff knew or could have found out about the suit's lack of merit before filing. There will often be substantial overlap between the evidence and findings on that issue and the evidence and findings on the merits. Where there is such an overlap, then improved accuracy on the merits will tend to have a strong influence on how accurately the tribunal can determine whether conduct is frivolous and hence on deterrence of such conduct. To the extent that accurate sanctioning of frivolous claims depends on the neutrality of the tribunal, the likelihood of beneficial carryovers from the trial on the merits seems, if anything, even higher.

Second, if improved accuracy on the merits leads to more appropriate actual sanctions for frivolous claims, we can be quite confident that those sanctions will actually influence the behavior of frivolous claimants. Such claimants normally have legal advice. On account of that advice, they will normally have a well-honed sense of how much harm their suit will do and of the applicable sanctions. Moreover, to the extent their motivation is financial rather than ideological, they will be strongly responsive to expected sanctions. The central concerns that cause Kaplow to be skeptical of the value of accuracy in other settings thus seem inapplicable here.

Apart from deterring litigation misconduct, accuracy on the merits can have desirable effects on claiming, settlement, and compliance behavior if litigants care about accuracy and are influenced by that concern. ${ }^{57}$

55 Kaplow, supra note 1 , at 312 \& n.7.

${ }^{56}$ Among other things, there is no consensus about what causes frivolous suits. Some theories emphasize asymmetric costs, some emphasize asymmetric information, and some emphasize timing problems. Cooter \& Rubinfeld, supra note 5, at 1083-84. The implications for frivolous claims of a particular procedure that made litigation more accurate might well be different under each of these theories.

57 The literature of dispute resolution generally suggests, for example, that the presence or absence of perceived bias is often a critical factor in the decision to resort to a third-party 
Suppose that achieving the appropriate level of deterrence for primary conduct depends on the willingness of a sufficient number of injured persons to claim. Suppose further that in a regime where not all actors discover their injuries or sue, those who are likely to do so are the sort of persons who assign a high value to accuracy. They may be more alert or mistrustful by nature, so that they tend to be especially aware of or to attach special importance to issues of bias. Alternatively, the events giving rise to suit may have made the potential claimant more sensitive to insult or distrustful. One might expect that most such cases will concern individuals (at least on the plaintiff's side) rather than institutions. But one cannot rule out the possibility that some institutions will be represented by agents with strong preferences for accuracy. ${ }^{58}$

Where actors care greatly about accuracy and the system does not provide it, claiming may be deterred. Individual civil rights cases may be an example. Enforcing laws against sexual harassment may require victims to come forward. But because of the nature of their injury and of the experiences giving rise to it, such victims may demand very strong evidence of the tribunal's lack of bias. Indeed, they may view such a process that fails to meet that demand as simply exacerbating their injuries. In such cases, failure to respond to the demand for more accurate procedures may strongly disserve enforcement policy.

Concern for accuracy may also figure in decisions whether to comply with judgments. The mechanism here is again linked to litigants' perceptions of fairness. ${ }^{59}$ Apart from its effect on litigation costs, noncompliance threatens substantive goals, particularly when the judgment declares future rights and obligations. The relationship between accuracy and compliance may be particularly important, for example, in civil rights suits

decision maker. For examples of this view as it emanates from theoretical writers, see Martin Shapiro, Courts: A Comparative and Political Analysis, at 17 (1981) ("The basic tension to be found in courts as conflict resolvers lies in their need to persuade the parties that judges and laws they have not chosen nonetheless constitute a genuine, neutral third."); Georg Simmel, The Sociology of Georg Simmel 151 (Kurt Wolff ed. 1950) ("The voluntary appeal to an arbitrator, to whom they submit from the beginning, presupposes a greater subjective confidence in the objectivity of judgment than does any other form of decision.").

${ }^{58}$ For a description of such a case, see Stephen McG. Bundy, Commentary on "Understanding Pennzoil v. Texaco": Rational Bargaining and Agency Problems, 75 Va. L. Rev. $335,344-45$ (1989). Where institutional agents have such preferences, those agents' decisions may not serve the institutions' interests. But to the extent that the agents' preferences continue to influence the public benefits and costs of disputing, we may still wish to design public procedures that respond to those preferences.

59 Again, there is some social psychological literature suggesting that compliance with court judgments is linked to the perceived fairness of the outcome. Lind \& Tyler, supra note 50 , at $81-82$. 
seeking institutional reform. Such cases seem likely to be marked by strong party attachment to the norms in dispute and distrust of the opponent, factors which may lead the parties to assign special importance to both avoiding random error and lack of bias. At the same time, effective relief may depend on the parties' willingness to comply with the judgment. In such cases, courts might wish to provide for more accuracy than Kaplow's behavioral account would suggest.

Finally, accuracy can also have precedential consequences for disputing behavior in other cases and, in particular, for settlement. ${ }^{60}$ In routine personal injury litigation, lawyers and settlement judges often rely on services that report jury verdicts and settlements to set a baseline for negotiations in comparable cases. ${ }^{61}$ Similar use of precedent often occurs in mass tort cases. One might expect that greater accuracy in earlier outcomes will be reflected both in the parties' willingness to use them as a device for facilitating negotiation and in the quality of settlements reached in partial reliance on them.

\section{Beyond Behavior}

For many observers of the legal system, accurate adjudication is not principally (or even primarily) a matter of improving behavior or reducing costs but instead a matter of respecting intangible legal rights, delivering corrective justice, or ensuring equal treatment. ${ }^{62}$ Such arguments are likely to seem more compelling within the expanded framework suggested here. In large part this is due to the inclusion of systemic bias. Where inaccuracy is due to systemic bias rather than random error, the argument that there is an independent injustice flowing from inaccuracy may well have much stronger intuitive appeal. A high level of random error, after all, can be seen as implying equal indifference to both parties. A high level of systemic bias, in contract, potentially implies inequality, subordination, or stigmatization of those against whom the bias operates-a

${ }^{60}$ Kaplow explicitly excludes precedential effects on settlement but does not spell out the consequences of the exclusion. Kaplow, supra note 1, at 328-29 \& $\mathbf{n} .53$.

61 Wayne D. Brazil, Effective Approaches to Settlement: A Handbook for Lawyers and Judges 460 (1988); Charles B. Craver, Effective Legal Negotiation and Settlement 127 (2d ed. 1993).

${ }^{62}$ See, for example, Ronald Dworkin, Principle, Policy, Procedure, in A Matter of Principle 72 (1985). Even advocates of rights-based theories must confront problems of scarce resources, though they do not do so comfortably. For excellent discussion of how rightsbased theories deal (or fail to deal) with such problems, see Robert G. Bone, Rethinking the "Day in Court" Ideal and Nonparty Preclusion, 67 N.Y.U. L. Rev. 193, 256-64 and esp. n.236. 
graver form of injustice. ${ }^{63}$ The chemical company case illustrates the point. The harm there is not just that lower sanctions give rise to increased harm and greater overdeterrence for African Americans. It is also that African Americans will suffer a disproportionate share of the increased total harm, increasing inequality. In addition, those African American litigants who choose to bring suit suffer the further injustice of having their own claims handled in a biased fashion. While for historical reasons these concerns may be most grave in cases of discrimination on the basis of race, gender, or religion, they are also present when the bias is against persons defined as outsiders by less controversial measures, such as citizenship of another state. ${ }^{64}$

Concerns about injustice, dignitary harms, or unequal treatment can be so strong that they counsel rejection of procedural arrangements that may be behaviorally superior. Return to the automobile personal injury case described above, in which African Americans receive damages that are too low, but suppose that instead of receiving $\$ 1,000$ in damages the majority victims receive an offsetting boost to their compensation, to $\$ 1,028$. For drivers who cannot predict the race of their victim, deterrence is the same as if there was no systemic bias because expected damages, given the increased payment to whites, equals $\$ 1,000$. Deterrence of bad driving is therefore optimal. For potential victims, the behavioral consequences again differ. Informed whites can be expected to engage in a little bit too much risky activity (again independent of whether they know the actual harm they will suffer). African Americans can, however, be expected to know of systemic bias against them and to be overdeterred from activities in which they run a risk of being injured by an automobile. Behaviorally, this scenario is arguably superior to (and certainly no worse than) the first scenario. But many persons, would, I think, regard it as worse than the former case because the disparate treatment of majority and minority victims has been exacerbated. ${ }^{65}$

\section{ApPlying the ExPanded Account}

What are the practical consequences of an expanded account, either for particular kinds of litigation or for particular kinds of procedures?

${ }^{63}$ To the extent the harm is experienced as psychic injury by individual actors, the benefits flowing from its elimination can be accounted for within an economic framework. The point here is that the argument for recognizing an additional intangible harm will seem stronger if systemic bias is taken into account.

64 See, for example, 28 U.S.C. § 1331.

65 One might generate a very similar intuitive response by shrinking the size of the disadvantaged minority. As one did so, deterrence would approach optimal levels, but the unfairness of disparate treatment might well be seen as increased. 
Much depends on matters beyond the scope of this discussion, including the general risk of systemic bias and the severity of its effects. My own imperfectly informed judgment is that the risk of systemic bias is substantial across a range of procedural settings. ${ }^{66}$

Much also depends on whether procedures that reduce random inaccuracy also tend to reduce bias. Again, it seems plausible to me that in most cases a procedure that reduces one will also reduce the other. ${ }^{67}$ Normally, for example, one would expect that rules which permit a more complete and balanced factual record, such as discovery rules, would both permit the drawing of finer distinctions and make it more difficult for tribunals to justify discriminatory decisions. ${ }^{68}$ Similarly, using a twelve-person civil jury (rather than a six-person one) may both improve resolving power and reduce bias. ${ }^{69}$

If these intuitions are right, then the expanded account would predict an upward revision in the value of procedures that reduce random inaccuracy, both because reduced random error is independently more valuable than in Kaplow's account and because such procedures reduce systemic bias. It follows that in such an account there will be fewer occasions when party incentives to seek accuracy are too great and more occasions on which some form of subsidy for accuracy might be warranted.

In an expanded account, the value of more accurate procedures should also be somewhat more consistent across different substantive areas than in Kaplow's account. In part that is because the effects of systemic bias in altering deterrence are more likely to translate into bad behavior across the substantive spectrum. In part it is because the unfairness of systemic bias is more severe and reflects values applicable in every procedural setting. $^{70}$

${ }^{66}$ For some of the evidence underlying that judgment, see notes 33-35 supra.

${ }^{67}$ If persons who are likely to be victims of systemic bias are also economically disenfranchised, it may be that the implementation of a particular procedure will depend on the availability of a subsidy.

${ }^{68}$ Compare Kaplow, supra note 1, at 397 (suggesting that procedures which allow for a more complete record may sometimes have these overlapping effects).

${ }^{69}$ Richard Lempert, Uncovering Nondiscernable Differences: Empirical Research and the Jury-Size Cases, 73 Mich. L. Rev. 643, 664-99 (1975) (suggesting this possibility).

${ }^{70}$ That is not to say, however, that the dangers of systemic bias are equally grave in all settings. I am less inclined than Kaplow, for example, to believe that procedural understandings developed primarily to protect against bias in criminal cases apply "comfortably" to government benefits programs (Kaplow, supra note 1, at 398), even though the government is a party in both settings and both settings involve many individuals vulnerable to systemic bias. It may be, for example: that the nonbehavioral harms of a mistaken finding of guilt are more severe than the nonbehavioral harms of a mistaken denial of benefits; that achieving the full value of accuracy in administering government benefits does not require giving government officials the same degree of discretion as would fall to prosecutors in a low enforcement effort, high-sanction criminal justice system; or that bureaucracies charged 
But even in an expanded account, Kaplow's basic insight that the value of accuracy "depend[s] greatly on the context" and "cannot be separated from how other aspects of the system are designed" will remain true and important. ${ }^{71}$ And consistent with that insight, there will remain some classes of cases where the expanded account adds little to Kaplow's analysis. For commercial disputes between businesses, involving issues of interest only to the parties, Kaplow's account seems wholly adequate. There is little risk of systemic bias, little likelihood of precedential effect, and little social interest in the parties' claiming behavior. ${ }^{72}$ Were it not for evidence of systemic bias, ${ }^{73}$ one might also want to concur unreservedly in the relatively low value his account assigns to accuracy in automobile personal injury cases, which appear to have few useful behavioral effects, ${ }^{74}$ where claiming behavior is wholly routinized, and where the presence of insurance may cause even individual disputants to behave like institutional actors.

In other settings, the expanded account would seem to reinforce the aspects of Kaplow's account that point to a relatively high value for accuracy. Consistent with more conventional accounts, for example, as-

with administering benefits are more likely to be benign or trustworthy than are police and criminal prosecutors. For discussion of the latter possibility, see, for example, Walters v. National Ass'n of Radiation Survivors, 473 U.S. 305 (1985); Bundy \& Elhauge, supra note 20, at 398-401 (1991); William Simon, Legal Informality and Redistributive Justice, 19 Clearinghouse Rev. 384 (1985).

${ }^{71}$ Kaplow, supra note 1, at 400. Kaplow's view is consistent with an emerging view among procedural scholars that civil process ought not to be designed transubstantively, that is, to operate uniformly across different kinds of disputes that demand more individualized treatment. See Stephen Subrin, How Equity Conquered Common Law: The Federal Rules of Civil Procedure in Historical Perspective, 135 U. Pa. L. Rev. 909, 985, 991, 995-96 (1987) (arguing that a major flaw of the Federal Rules of Civil Procedure is that they operate transubstantively); Robert Cover, For James Wm. Moore: Reflections on a Reading of the Rules, 84 Yale L. J. 718 (1975) (same).

72 It is certainly no accident that these aspects of commercial litigation also are cited by procedural reformers who favor increased use of alternative dispute resolution (ADR) in such cases. See Wayne D. Brazil, A Close Look at Three Court-sponsored ADR Programs: Why They Exist, How They Operate, What They Deliver, and Whether They Threaten Important Values, 1990 U. Chi. Legal F. 303, 317 (urging ADR for cases where "commercial entities" oppose each other and nothing is at stake but money); Brazil, supra note 61, at 2 (suggesting that most commercial cases have no significant analogues).

${ }^{73}$ Chin \& Peterson, supra note 35 . Even this concern might be eliminated if the adoption of damage schedules for such cases reduced fact-finding discretion and hence the influence of decision-maker bias. In such cases, the expanded account might even reinforce Kaplow's implicit case for procedures that reduce accuracy since formal damage schedules could reduce both litigation costs and the behavioral and nonbehavioral harms of systemic bias, without generating significant harms on account of increased random error.

74 Compare Kaplow, supra note 1, subsection IIA1, with Stephen D. Sugarman, Doing Away with Tort Law, 73 Calif. L. Rev. 555, 559-73 (1985). For both authors, it is important that drivers cannot predict how much damage their actions will cause and that most drivers decide how safely or dangerously to drive without regard to the level of expected sanctions for doing so. 
pects of Kaplow's account imply a relatively high value for the reduction of random error in civil rights cases seeking injunctive relief. ${ }^{75}$ The expanded account, which would give weight both to problems of systemic bias and to compliance effects, would seem to reinforce that implication.

The expanded account also seems to strengthen the case for accuracy in certain kinds of actions for money damages, such as individual civil rights, tort, and employment claims pitting individuals against organizations. It may be that many of these cases involve conduct where defendants have only a hazy sense of how much harm they are doing. Nonetheless, on the reasonable assumption that claimants are likely to be relatively risk-averse and institutional defendants relatively risk-neutral, Kaplow's account suggests that accuracy in determining damages will be socially desirable. ${ }^{76}$ The expanded account would appear to strengthen the case for greater accuracy in such cases, which frequently involve risks of systemic bias, precedential effects for primary conduct or for other related cases, and (more speculatively) a relatively strong relationship between perceived accuracy and claiming and compliance behavior.

Where the goals of avoiding random inaccuracy and systemic bias diverge, however, the expanded view could produce dramatic reversals of Kaplow's account. In such cases, the greater value of systemic bias could lead to rejecting a procedure that would reduce random error, even if it were less costly and would (apart from its influence on systemic bias) tend to improve behavior. One example is diversification of the federal judiciary along racial, ethnic, and gender lines. Diversification may be essential to eliminate (or at least ameliorate) the behavioral and nonbehavioral harms of bias by moving mean outcomes in adjudication closer to the true average. But it is also plausible that in a truly diverse court the severity of errors around the (accurate) mean may also be much broader because individual judges vary much more widely in their evaluation of individual cases.

Alternatively, consider the criminal jury. An important school contends that the use of juries decreases the ability to draw fine distinctions and increases random error. ${ }^{77}$ To the extent this is true, Kaplow's account

75 Compare Kaplow, supra note 1, subsection IVB1-2, with Abram Chayes, The Role of the Judge in Public Law Litigation, 89 Harv. L. Rev. 1281, 1297-98 (1976). For both, the critical element is that the adjudication specifies future rights and obligations.

${ }^{76}$ Greater accuracy will reduce risk for claimants, which is desirable. Greater accuracy will increase risk for defendants, but that should have no influence on risk-neutral defendants. See note 21 supra.

$\pi$ A fountainhead for this view is Jerome Frank, Courts on Trial: Myth and Reality in American Justice 108-25 (1949). For more recent debate, compare Marc Galanter, The Civil 
would seem to predict stronger support for the use of the jury in determining damages in tort cases (where errors will have little effect on behavior) than in criminal cases (where, on Kaplow's account, the value of reducing error is greatest). ${ }^{78}$ In fact, however, the opposite appears to be true: those who are most critical of the civil jury on the ground of imprecision tend to strongly support the use of the criminal jury. ${ }^{79}$

Widespread acceptance of the criminal jury can be understood as reflecting concerns about systemic bias. The traditional account emphasizes the prevention of systemic bias against political opponents. ${ }^{80}$ In a present-day account, the emphasis might shift to the prevention of bias against racial minorities, who in many communities make up a disproportionately large share of criminal defendants and a disproportionately small share of full-time criminal justice system personnel. ${ }^{81}$ In either case, greater random variation in decisions might be viewed as the price of reduced bias. ${ }^{82}$

The harms of systemic bias-and hence the justification for the jury as a corrective against bias, despite its imprecision-might well be especially great in the sort of low enforcement, costly sanction regime that Kaplow characterizes as optimal for criminal cases. In such a regime, a smaller fraction of actual offenders will be detected and punished, and there will probably be substantial police and prosecutorial discretion. A modest degree of bias in the selection of cases to prosecute might therefore result in a very substantial reduction in deterrence for beneficia-

Jury as Regulator of the Litigation Process, 1990 U. Chi. Legal F. 201, 204-9 (discussing and rejecting the critical view), with Peter Huber, Junk Science and the Jury, 1990 U. Chi. Legal F. 273, 276-90 (describing large and spectacular jury errors on findings of liability and damages).

${ }^{78}$ In this, Kaplow also agrees with more conventional views, although for different reasons. Compare Kaplow, supra note 1, subsection IILA2b, subsection IVA2, with Dworkin, supra note 62, at 72-92 (1985).

79 See, for example, Duncan v. Louisiana, 391 U.S. 145, 157 (1968) (noting that "some of the severest critics of civil juries acknowledge that the arguments for criminal juries are much stronger').

${ }^{80}$ Duncan v. Louisiana, 391 U.S. 145, 156 (1968) ("Those who wrote our constitutions knew from history and experience that it was necessary to protect against unfounded criminal charges brought to eliminate enemies and against judges too responsive to the voice of higher authority.").

81 Evidence about racial discrimination by juries, while disturbing, does not necessarily undermine this account. It could be that discrimination would be more severe without juries.

${ }^{82}$ Compare Mirjan R. Damaska, The Faces of Justice and State Authority 26 (1986) ("A certain amount of disorder must be accepted as the price of the fundamental commitment to a wider distribution of power." ). 
ries, grave overdeterrence for victims of bias, and gross inequality of treatment.

Taking account of systemic bias, then, might lead to a more complex appreciation of the benefits of accuracy in criminal cases, even if those benefits are viewed in narrowly economic terms. That appreciation would balance some underlying economic considerations that point toward an approach that features low enforcement effort, high sanctions, and low random error against other economic considerations that point to the value of controlling systemic bias. If noneconomic factors are taken into account, they seem likely to tip the balance further toward preventing bias. The resulting procedure may be an uneasy hybrid not readily subject to formal analysis but superior to the alternatives on both behavioral and nonbehavioral grounds.

\section{Conclusion}

Accuracy is a central aspiration of any procedural system, but it cannot be the only aspiration. Kaplow's exceptionally imaginative and careful account teaches us a lot about how we should think, within a deterrence framework, about trade-offs between accuracy and other values. Nonetheless, it is importantly incomplete. The supplemental account presented here argues that procedures that reduce random error can generate value in other ways, by eliminating systemic bias, through indirect effects on deterrence and compliance with the law, and by improving the conduct of litigants. Taking account of these supplemental considerations will often result in assigning a different value to procedures that reduce random inaccuracy, and often that value will be higher than in Kaplow's account. 
HeinOnline -- 23 J. Legal Stud. 4341994 